\title{
Control of the Austenite Recrystallization in Niobium Microalloyed Steels
}

\author{
Stephanie Vervynckt ${ }^{1, a}$, Kim Verbeken ${ }^{1,2^{2} b}$, Philippe Thibaux ${ }^{3, c}$, \\ Martin Liebeherr ${ }^{3, \mathrm{~d}}$ and Yvan Houbaert ${ }^{1, \mathrm{e}}$ \\ ${ }^{1}$ Ghent University, Department of Materials Science and Engineering, Technologiepark 903, B- \\ 9052 Gent, Belgium \\ ${ }^{2}$ Max-Planck-Institut für Eisenforschung, Max-Planck-Strasse 1, 40237 Düsseldorf, Germany \\ ${ }^{3}$ OCAS N.V., ArcelorMittal R\&D Industry Ghent, J.F. Kennedylaan 3, B-9060 Zelzate, Belgium \\ K. Verbeken, Postdoctoral Fellow of the Fund for Scientific Research F.W.O.-Vlaanderen - \\ Belgium

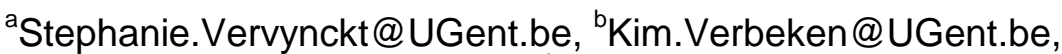 \\ 'Philippe.Thibaux@ArcelorMittal.com, ${ }^{\mathrm{d}}$ Martin.Liebeherr@ArcelorMittal.com, \\ eYvan.Houbaert@UGent.be
}

Keywords: Recrystallization, precipitation, double deformation, $\mathrm{Nb}$ microalloyed steels

\begin{abstract}
The use of heavy gauge steel sheets for structural applications very often requires a combination of high yield strength and adequate toughness. The most cost effective way to realize a high yield strength and a high ductility in a low alloyed steel is grain refinement. In industrial practice, this refinement is realized by controlled processing. This process consists of controlling the slab reheating temperature, applying a large amount of hot deformation below the nonrecrystallization temperature $\left(\mathrm{T}_{\mathrm{nr}}\right)$ and accelerated cooling. A better knowledge of $\mathrm{T}_{\mathrm{nr}}$ could optimize the process and the best mechanical properties could be reached against the lowest cost. $\mathrm{T}_{\mathrm{nr}}$ can be raised by the addition of microalloying elements such as $\mathrm{Nb}$. Nb can retard the static recrystallization of austenite at low temperatures either by solute drag or by precipitation pinning. In this study, the recrystallization behavior of five $\mathrm{Nb}$-microalloyed model alloys with various $\mathrm{Nb}$ contents, was evaluated by double hit compression tests. Further, the precipitation state of the materials was investigated experimentally by Inductively Couples Mass Spectroscopy and X-ray Diffraction. The construction of recrystallization-time-temperature diagrams and precipitation-timetemperature diagrams showed that both mechanisms, i.e. recrystallization and precipitation, strongly influence each other.
\end{abstract}

\section{Introduction}

A good combination of strength and toughness in HSLA steels can be achieved by the addition of microalloying elements such as $\mathrm{Nb}$ and $\mathrm{Ti}$ [1]. The effect of Ti is more or less incontestable, i.e. the formation of TiN precipitates inhibits grain growth, whereas the role of $\mathrm{Nb}$ in retarding the austenite recrystallization in HSLA steels has been the subject of considerable interest and discussion over the past 30 years [2-4]. Hutchinson et al. [5] suggested that the retardation of austenite recrystallization in $\mathrm{Nb}$-containing steels results from the pinning of austenite grain boundaries and subboundaries by either niobium carbonitride precipitation and/or by niobium atoms in solid solution in austenite. So far it is not possible to distinguish well between the effect of both mechanisms, i.e. solute drag and precipitation pinning. Speer and Hansen [3] investigated the austenite recrystallization in $\mathrm{Nb}$ microalloyed steels, showing that the solute drag effects on the austenite recrystallization are very small compared to the effect of carbonitride precipitation. Nevertheless, other investigators argue strongly in favor of the solute drag effect [6] or of a combination of the both effects [7]. The objective of the present paper is to separate both retarding mechanisms, by investigating model alloys designed to show either extensive or almost no 
precipitation. Moreover, the recrystallization kinetics of five $\mathrm{Nb}$-microalloyed steels during hot deformation is linked with the morphology and composition of the precipitates found in these materials. The goal of this work is to contribute to the understanding of the fundamental mechanisms responsible for the retardation of austenite recrystallization in $\mathrm{Nb}$-microalloyed steels.

\section{Experimental Setup}

Five model alloys were designed and casted as $100 \mathrm{~kg}$ ingots in a Pfeiffer vacuum furnace operated under argon gas atmosphere. The chemical composition of these alloys can be found in Table 1 . The $\mathrm{C}-\mathrm{Mn}$-reference alloy, without additional $\mathrm{Nb}$, represents a reference steel. The second, the third and the fourth alloy, containing $0.02,0.08$ and $0.16 \mathrm{wt} \%$ of $\mathrm{Nb}$, respectively, allowed to study the effect of $\mathrm{Nb}$ on the recrystallization and precipitation kinetics. Finally, the fifth alloy (C-Mn-Nb-N) was designed to study the influence of $\mathrm{N}$ on the recrystallization and precipitation behavior.

\begin{tabular}{lccccccc}
\hline & $\mathrm{C}$ & $\mathrm{Mn}$ & $\mathrm{Si}$ & $\mathrm{Al}$ & $\mathrm{Nb}$ & $\mathrm{Ti}$ & $\mathrm{N}$ \\
\hline C-Mn Reference & 0.02 & 1.5 & 0.26 & 0.043 & - & $20 \mathrm{ppm}$ & $18 \mathrm{ppm}$ \\
C-Mn-0.02Nb & 0.02 & 1.5 & 0.24 & 0.043 & 0.021 & $10 \mathrm{ppm}$ & $5 \mathrm{ppm}$ \\
C-Mn-0.08Nb & 0.02 & 1.5 & 0.24 & 0.044 & 0.082 & $15 \mathrm{ppm}$ & $6 \mathrm{ppm}$ \\
C-Mn-0.16Nb & 0.02 & 1.5 & 0.26 & 0.067 & 0.17 & $80 \mathrm{ppm}$ & $20 \mathrm{ppm}$ \\
$\mathrm{C}-\mathrm{Mn}-0.16 \mathrm{Nb}-\mathrm{N}$ & 0.02 & 1.5 & 0.26 & 0.033 & 0.18 & $45 \mathrm{ppm}$ & $66 \mathrm{ppm}$ \\
\hline
\end{tabular}

Table 1. Chemical composition of the alloys (in wt\% unless stated otherwise)

The cast blocks were thermomechanically processed under conditions comparable to those during industrial steel plate rolling. This means that, after a reheating cycle of two hours at $1200^{\circ} \mathrm{C}$, two pre-rolling steps with $20 \%$ of deformation each were given above $1100^{\circ} \mathrm{C}$. Before finish rolling, the plate was air cooled until a temperature of $900^{\circ} \mathrm{C}$ was reached. Finishing was performed in five passes with a total reduction of $55 \%$. After finish rolling at $820^{\circ} \mathrm{C}$, the plates were air cooled to room temperature.

The isothermal recrystallization kinetics were determined from double hit compression tests with various interpass times. For these tests, cylindrical samples with a diameter of $5 \mathrm{~mm}$ and a height of $10 \mathrm{~mm}$ were machined by spark-erosion; the axis of the sample being parallel to the normal direction of the plate. The specimens were tested in vacuum under uni-axial conditions in a Bähr ${ }^{\circledR}$ dilatometer equipped with an induction coil and a deformation unit. After reheating for 5 minutes at $1250^{\circ} \mathrm{C}$ and subsequent cooling at a cooling rate of $1^{\circ} \mathrm{C} / \mathrm{s}$ to a chosen deformation temperature, a first deformation pass with a strain of 0.2 and a strain rate of $0.5 / \mathrm{s}$ was given. After deformation, the stress was immediately relieved to a minimum value necessary to keep the sample in position. After different chosen waiting times, a second deformation pass (also with $\varepsilon=0.2, \mathrm{~d} \varepsilon / \mathrm{dt}=0.5 / \mathrm{s}$ ) was applied. Subsequently, the samples were helium quenched to study the precipitation state. The total amount of niobium precipitated was analyzed by Inductively Coupled Plasma Mass Spectrometry (ICP-MS) on the quenched samples. In these experiments, a small amount of material is selectively dissolved and the resulting solution is filtered through a $20 \mathrm{~nm}$ pore size filter. The filtrate contains the dissolved Fe-matrix together with the elements in solid solution, while the filter traps the insoluble precipitates. The weight fraction of $\mathrm{Nb}$ on the filter and in the filtrate was quantitatively determined. Furthermore, the stoichiometry of the precipitates was determined by performing XRay Diffraction (XRD) analysis on the filters. For the radiation a $\mathrm{Cu}-\mathrm{K} \alpha$ source was used.

\section{Results en discussion}

Recrystallization kinetics. The isothermal recrystallization kinetics were studied by means of double-hit compression tests with variable interpass times. The recrystallized fraction was determined with the help of the second stress-strain curve. If the interpass time is sufficiently long 
enough for full softening to occur, the second flow curve should be identical to the first flow curve. If there is no softening at all, the second flow curve should appear as an extrapolation of the first flow curve. In order to quantify the amount of softening between these extremes, the $2 \%$ offset method was used. With that method the softening effects by recovery can be neglected [8] and consequently the calculated softening fraction is linearly related to the statically recrystallized volume fraction. The evolution of the recrystallized fractions with time for all these materials is displayed in Figure 1, showing in all cases that decreasing the temperature slows down the recrystallization kinetics. In the $\mathrm{Nb}$ microalloyed steels, the formation of a plateau, which interrupts the Avrami or sigmoidal shape of the curve, is caused by a temporary or permanent recrystallization stop. This recrystallization stop originates from the pinning of the grain boundaries by precipitates. For the $\mathrm{C}-\mathrm{Mn}-0.02 \mathrm{Nb}$ alloy, this plateau appears at $875^{\circ} \mathrm{C}$ and $850^{\circ} \mathrm{C}$. For the $\mathrm{C}-\mathrm{Mn}-0.08 \mathrm{Nb}$ alloy and the $\mathrm{C}-\mathrm{Mn}-0.16 \mathrm{Nb}$ alloy, this plateau appears for the first time at $900^{\circ} \mathrm{C}$ and $1025^{\circ} \mathrm{C}$, respectively. For the C-Mn- $0.16 \mathrm{Nb}-\mathrm{N}$ alloy, precipitates are found to hinder the recrystallization at all tested temperatures. The nature of the precipitates, responsible for this recrystallization stop, is discussed in the next section.
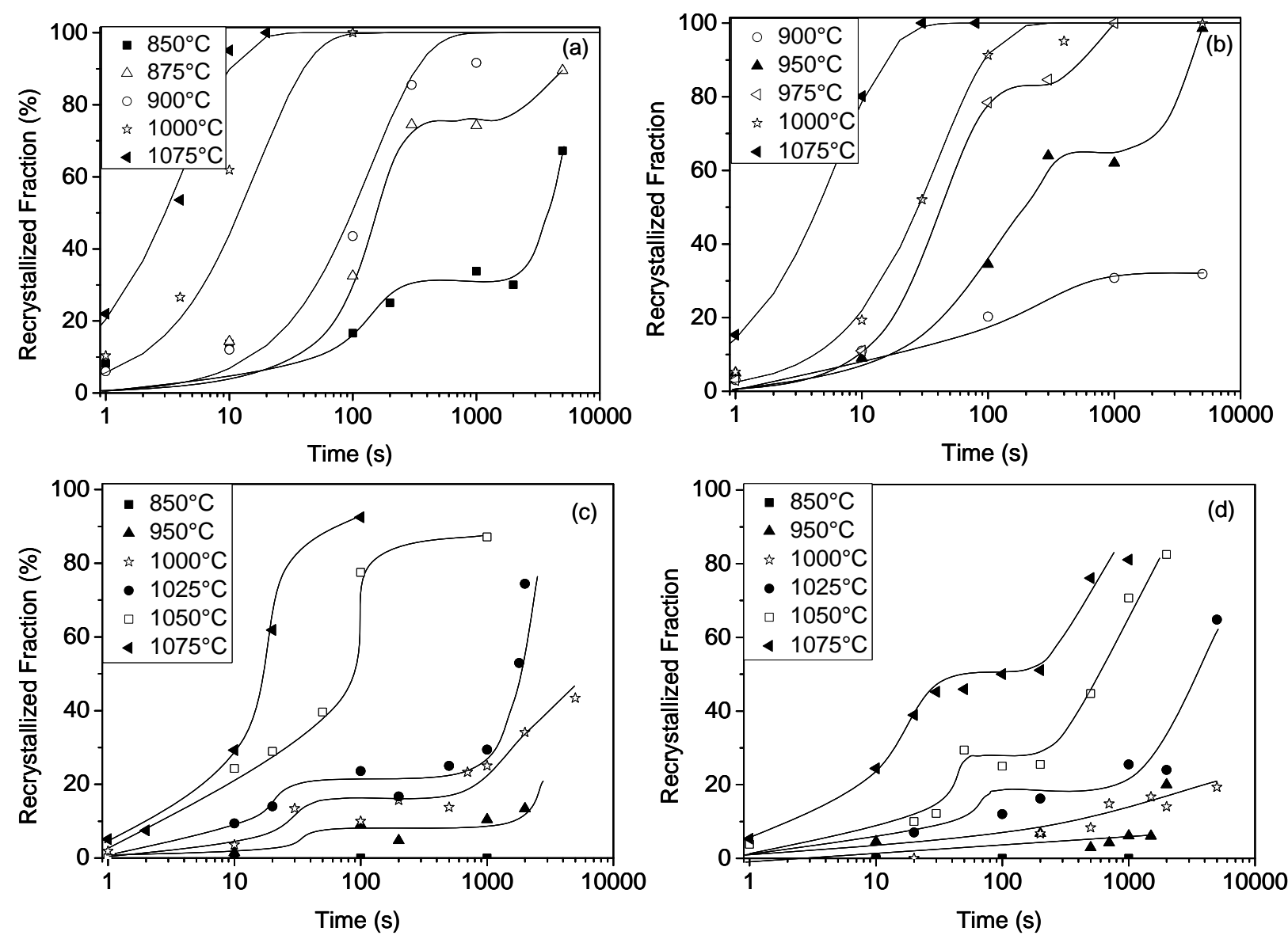

Figure 1. Recrystallized fractions plotted against time, as determined from double deformation tests with $\varepsilon=0.2$ and $d \varepsilon / d t=0.5 /$ s. (a) C-Mn-0.02Nb, (b) C-Mn-0.08Nb, (c) C-Mn-0.16Nb and (d) C-Mn-0.16Nb-N.

Precipitation kinetics. The results of the recrystallization kinetics demonstrated some differences between the recrystallization behavior of the $\mathrm{C}-\mathrm{Mn}-\mathrm{Nb}$ and the $\mathrm{C}-\mathrm{Mn}-\mathrm{Nb}-\mathrm{N}$ alloy at $1050^{\circ} \mathrm{C}$ and $1075^{\circ} \mathrm{C}$. Therefore, the precipitated weight fraction of $\mathrm{Nb}$ was determined experimentally by ICPMS. The results can be found in Table 2 . At temperatures of $1075^{\circ} \mathrm{C}$ and $1050^{\circ} \mathrm{C}$, the amount of $\mathrm{Nb}$ precipitated in the $\mathrm{C}-\mathrm{Mn}-\mathrm{Nb}-\mathrm{N}$ alloy was remarkably higher than the amount of $\mathrm{Nb}$ precipitated in the $\mathrm{C}-\mathrm{Mn}-\mathrm{Nb}$ alloy. Thermodynamic equilibrium calculations [9] ascribed the higher fraction of $\mathrm{Nb}$ precipitated in the $\mathrm{C}-\mathrm{Mn}-\mathrm{Nb}-\mathrm{N}$ alloy to the formation of $\mathrm{NbN}$ and/or $\mathrm{NbCN}$. 


\begin{tabular}{lll}
\hline Material & Testing conditions & Nb precipitated \\
\hline $\mathrm{C}-\mathrm{Mn}-0.16 \mathrm{Nb}$ & $\mathrm{T}_{\text {def }}=1050^{\circ} \mathrm{C}, \mathrm{t}_{\mathrm{ip}}=50 \mathrm{~s}$ & $0.02 \mathrm{wt} \%$ \\
$\mathrm{C}-\mathrm{Mn}-0.16 \mathrm{Nb}$ & $\mathrm{T}_{\text {def }}=1075^{\circ} \mathrm{C}, \mathrm{t}_{\mathrm{ip}}=100 \mathrm{~s}$ & $0.013 \mathrm{wt} \%$ \\
$\mathrm{C}-\mathrm{Mn}-0.16 \mathrm{Nb}-\mathrm{N}$ & $\mathrm{T}_{\text {def }}=1050^{\circ} \mathrm{C}, \mathrm{t}_{\mathrm{ip}}=500 \mathrm{~s}$ & $0.04 \mathrm{wt} \%$ \\
$\mathrm{C}-\mathrm{Mn}-0.16 \mathrm{Nb}-\mathrm{N}$ & $\mathrm{T}_{\text {def }}=1075^{\circ} \mathrm{C}, \mathrm{t}_{\mathrm{ip}}=500 \mathrm{~s}$ & $0.026 \mathrm{wt} \%$ \\
\hline
\end{tabular}

Table 2. Precipitated mass fraction of $\mathrm{Nb}$ as experimentally determined on ICP-MS filters. The filters were prepared from quenched samples after double deformation. $\left(T_{\text {def }}=\right.$ deformation temperature, $t_{i p}=$ interpass time $)$

To prove the existence of the $\mathrm{NbN}$, the stoichiometry of the present precipitates is determined with $X$-ray diffraction. From the positions of the peaks in the intensity vs. $2 \theta$ spectrum, the lattice parameter, and thus the stoichiometry of the present precipitates could be determined. The method of measuring the filter, which only contains precipitates and not the complete as deformed material, i.e. precipitates and matrix, has the advantage that the peaks due to precipitation cannot overlap with matrix peaks and/or do not disappear in the background of the matrix. Six filters were measured and the results are presented in Figure 2.

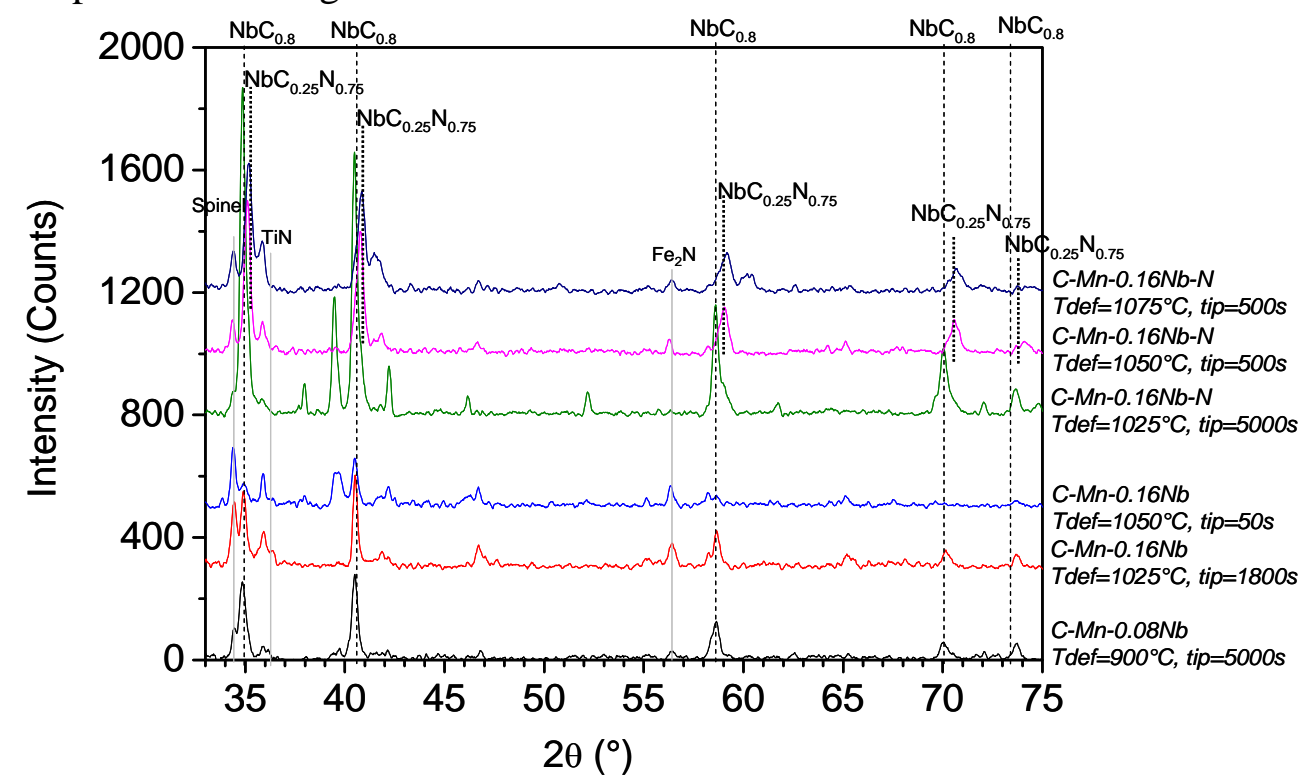

Figure 2. Stoechiometry of the precipitates by XRD-measurements on ICP-MS filters. Experimental conditions are shown on the figure.

Evidence of $\mathrm{NbC}_{0.8}$ (cubic) precipitates with a lattice parameter of $0.445 \mathrm{~nm}$ was found in the $\mathrm{C}-\mathrm{Mn}-0.08 \mathrm{Nb}$ alloy, in the $\mathrm{C}-\mathrm{Mn}-0.16 \mathrm{Nb}$ alloy and in the $\mathrm{C}-\mathrm{Mn}-0.16 \mathrm{Nb}-\mathrm{N}$ alloy at $1025^{\circ} \mathrm{C}$. However, in the C-Mn- $0.16 \mathrm{Nb}-\mathrm{N}$ alloy at $1050^{\circ} \mathrm{C}$ and $1075^{\circ} \mathrm{C}$, the peaks appear to be a little bit shifted towards higher angles. This shift corresponds to a somewhat lower lattice parameter of $0.441 \mathrm{~nm}$ indicating the presence of more nitrogen in the precipitates. Knowing this lattice parameter, the $\mathrm{C}$ and $\mathrm{N}$ content in the precipitate could be determined according to Vegard's law [10]. In that way, a stoichiometry of $\mathrm{NbC}_{0.25} \mathrm{~N}_{0.75}$ was found from the $\mathrm{X}$-ray spectrum. The found stoichiometries of the precipitates are in good agreement with those calculated under equilibrium conditions [9]. This confirms the statement of Pandit et al. [11] who declared that deformation will greatly enhance the kinetics of precipitation but that the nature and the chemical composition of the precipitates is expected to remain the same as in the case without deformation.

After the identification of the precipitates, a precipitation-time-temperature diagram can be constructed, see Figure 3. The precipitation start time $\left(\mathrm{P}_{\mathrm{s}}\right)$ and the precipitation finishing time $\left(\mathrm{P}_{\mathrm{f}}\right)$ were directly derived from Figure 1 as the start and the end of the plateau in the recrystallization versus time curves. In Figure 3 several horizontal lines, which correspond to the solubility temperatures of $\mathrm{NbC}$ and $\mathrm{NbN}$, are shown. These lines act as asymptotic lines to the curves $\mathrm{P}_{\mathrm{s}}$ and $\mathrm{P}_{\mathrm{f}}$. It can be seen that the nose temperature, corresponding to the temperature at which precipitation occurs in the minimum time, depends on the amount of microalloying elements. The nose 
temperature is higher for the steels with a higher $\mathrm{Nb}$ content. Furthermore, it is noticed that with higher $\mathrm{Nb}$ content also the minimum incubation time becomes shorter. Similar results were found by Medina and Quispe [12] for $\mathrm{Nb}, \mathrm{V}$ and $\mathrm{Ti}$ microalloyed steels. Not only the content of the $\mathrm{Nb}$ affect the value of $\mathrm{P}_{\mathrm{s}}$, but also the non-metallic components, i.e. $\mathrm{C}$ and $\mathrm{N}$, have an influence. Adding $\mathrm{N}$ to a $0.16 \mathrm{wt} \% \mathrm{Nb}$ microalloyed steel, results in the formation of $\mathrm{NbN}$ precipitates at high temperatures and slows down the precipitation of $\mathrm{NbC}$ at lower temperatures.

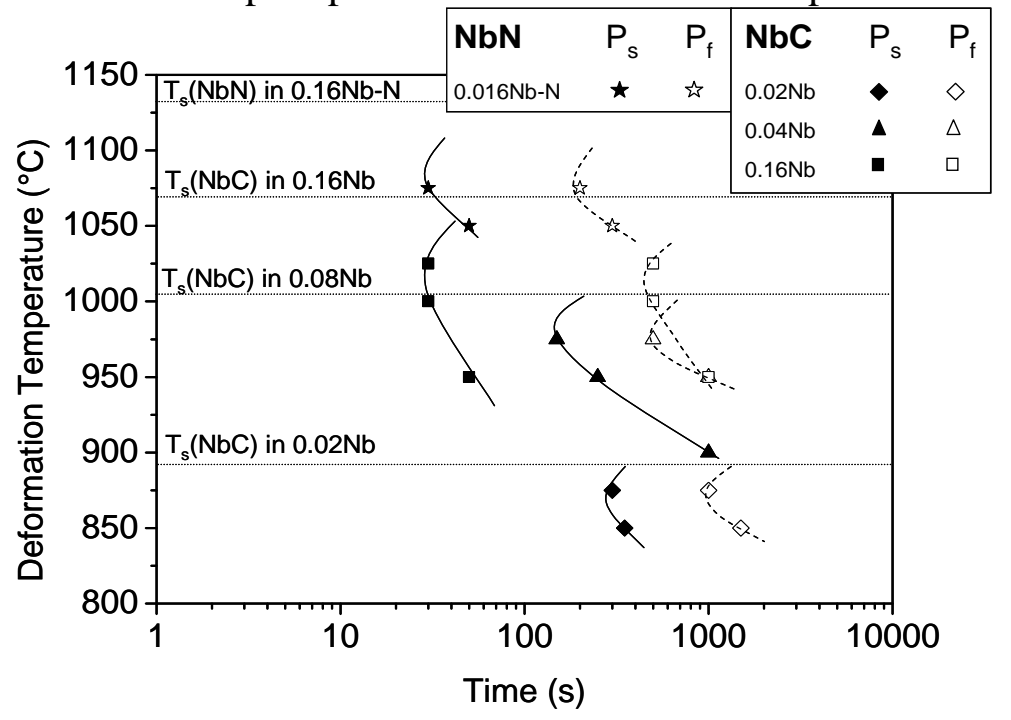

Figure 3. Precipitation-time-temperature diagrams for the five experimental steels. Plotted is the precipitation start time $\left(\mathbf{P}_{\mathrm{s}}\right)$ and the precipitation finishing time $\left(\mathbf{P}_{\mathrm{f}}\right)$.

Solute drag. As shown in Table 2, at high deformation temperatures a rather high amount of $\mathrm{Nb}$ is still present in solution and will conduct a drag force on the grain boundaries during recrystallization. This solute drag effect can be quantified by the construction of $50 \%$ softeningtime-temperature diagrams, see Figure 4. The solid lines in this figure correspond to the experimental times to achieve $50 \%$ of recrystallization $\left(\mathrm{t}_{0.5}\right)$ and were obtained directly from Figure 1. The dashed lines in Figure 4 correspond to the $\mathrm{Nb}$ solute drag lines of $0.02 \mathrm{wt} \%, 0.08 \mathrm{wt} \%$ and $0.16 \mathrm{wt} \% \mathrm{Nb}$, respectively, and represent the $\mathrm{t}_{0.5}$ that would be found if the delay in recrystallization was only due to solute drag. The procedure to construct such solute drag lines is explained more in detail in other work of the present authors. [9]

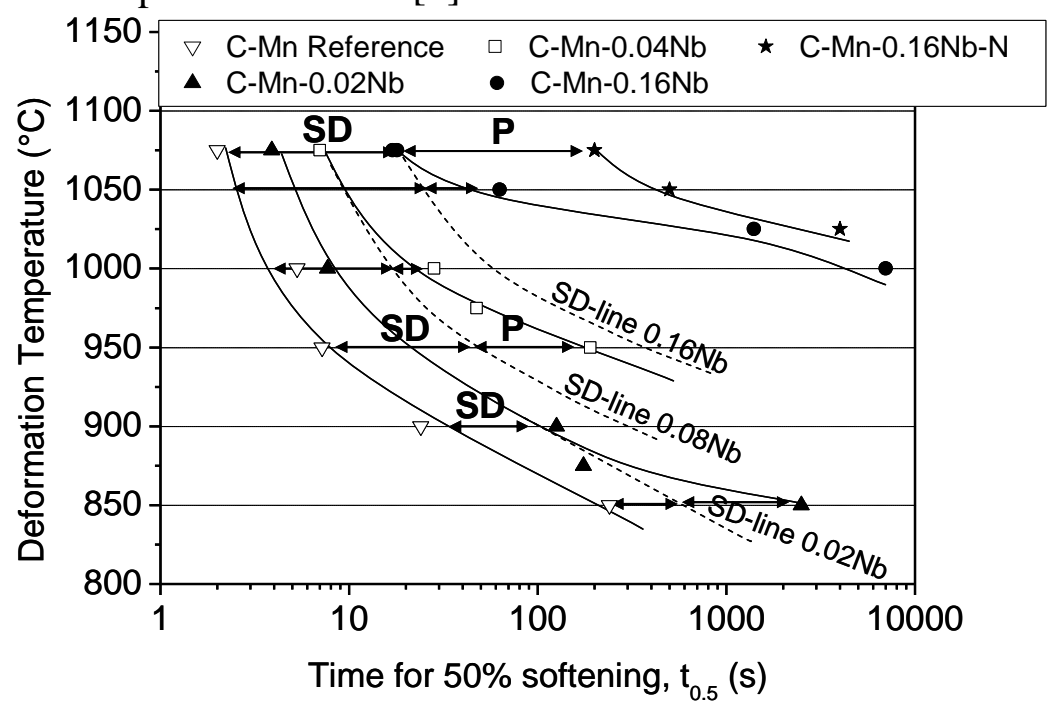

Figure 4. Recrystallization-time-temperature diagrams for the five experimental steels. Plotted is the time for $50 \%$ of recrystallization; $\mathrm{SD}=$ solute drag, $\mathrm{P}=$ precipitation.

From Figure 4, it can be seen that the C-Mn-Nb-N steel deviates from the Nb solute drag line at all temperatures tested. It is concluded that the retardation of the recrystallization behavior in this steel 
at all temperatures is caused by a combination of solute drag and precipitation. In Figure 7, the former is indicated as SD and the latter as P. While on a logarithmic scale the magnitude of the solute drag effect is almost constant over the complete temperature range, the magnitude of the precipitation effect seems to increase with decreasing temperatures. XRD measurements showed that, at $1075^{\circ} \mathrm{C}$ and at $1050^{\circ} \mathrm{C}, \mathrm{NbN}$ precipitates are responsible for the delay, while at $1025^{\circ} \mathrm{C}$ it is mainly $\mathrm{NbC}$. The fact that at $1025^{\circ} \mathrm{C}$ the $\mathrm{t}_{0.5}$-curve of the $\mathrm{C}-\mathrm{Mn}-\mathrm{Nb}-\mathrm{N}$ steel approaches the $\mathrm{t}_{0.5}$ curve of the $\mathrm{C}-\mathrm{Mn}-\mathrm{Nb}$ steel, where only $\mathrm{NbC}$ precipitates, confirms this. The $\mathrm{C}-\mathrm{Mn}-\mathrm{Nb}$ steel starts to deviate from the $\mathrm{Nb}$ solute drag line at temperatures of $1050^{\circ} \mathrm{C}$. ICP-MS measurements verified that there was already a small amount of $\mathrm{Nb}$ precipitated at that temperature which is probably insufficient to cause a plateau in the softening curve. Similarly the C-Mn- $0.08 \mathrm{Nb}$ and the C-Mn$0.02 \mathrm{Nb}$ alloy start to deviate form the $\mathrm{Nb}$ solute drag line at $1000^{\circ} \mathrm{C}$ and $875^{\circ} \mathrm{C}$, respectively. Again these temperatures correspond to the temperatures where a plateau appears for the first time in recrystallization versus time curves, see Figure 1. XRD measurements confirmed that the precipitates responsible for this temporary recrystallization stop were again $\mathrm{NbC}$.

\section{Conclusions}

1) Adding $\mathrm{Nb}$ to a $\mathrm{C}-\mathrm{Mn}$ reference alloy significantly retards the recrystallization kinetics by solute drag and by precipitation of $\mathrm{NbC}$. Adding extra $\mathrm{N}$ to a C-Mn- $0.16 \mathrm{wt} \% \mathrm{Nb}$ influences the recrystallization behavior which it delays strongly by the precipitation of fine $\mathrm{NbN}$ particles. These $\mathrm{NbN}$ particles were not found in the C-Mn-Nb steel with only $20 \mathrm{ppm}$ of $\mathrm{N}$.

2) It was proven that softening - time - temperature diagrams contain a lot of information on the precipitation state of the material. By drawing the solute drag line, the precipitation start temperature is found as the temperature at which $\mathrm{t}_{0.5}$ starts to deviate from this solute drag line. By comparing the distance between the $\mathrm{t}_{0.5}$ of a reference alloy and the solute drag line with the distance between the solute drag line and the $\mathrm{t}_{0.5}$ of a microalloyed steel, a quantification of the solute drag effect and the precipitation effect can be made at all temperatures.

\section{References}

[1] T.M. Maccagno, J.J. Jonas, S. Yue, B.J. McCrady, R. Slobodian, D. Deeks, ISIJ Int., Vol. 34 (1994), p. 917.

[2] C.M. Sellars: Proc. of Int. Conf. on Hot Working and Forming Processes, ed. by C.M. Sellars and G.J. Davies, Met. Soc., London, (1980), p. 3.

[3] J. G. Speer, S. S. Hansen, Metall. Trans. A, Vol. 20 (1989), p. 25.

[4] S.F. Medina, A. Quispe, P. Valles, J.L. Banos, ISIJ int., Vol. 39 (1999), p. 913.

[5] C.R. Hutchinson, H.S. Zurob, C.W. Sinclair, Y.J.M Brechet, Scr. Mater., Vol. 59 (2008), p.635.

[6] R. Coladas, J. Masounave, J. P. Bailon, Proc. Int. Conf. on the Hot Deformation of Austenite, TMS-AIME, New York, (1977), p. 341.

[7] H. L. Andrade, M. G. Akben, J. J. Jonas, Metall. Trans. A, Vol. 14 (1983), p. 1967.

[8] S. Vervynckt, K. Verbeken, P. Thibaux, Y. Houbaert, submitted to Met. Mat. Trans. (2009).

[9] S. Vervynckt, K. Verbeken, P. Thibaux, M. Liebeherr, Y. Houbaert, accepted by ISIJ int. (2008).

[10] A.R. Denton, N.W. Ashcroft, Phys. Rev. A, Vol. 43 (1991), p. 3161.

[11] A. Pandit, A. Murugaiyan, A. Saha Podder, A. Haldar, D. Bhattacharjee, S. Chandra, R.K. Ray, Scr. Mater., Vol. 53, (2005), p. 1309.

[12] S.F. Medina, A. Quispe, Steels Research, Vol. 67, no. 6 (1996), p. 257. 